\title{
Isolation and Characterization of Salmonella Enterica Serovar Typhimurium Circulating Among Healthy Chickens of Bangladesh
}

\author{
Md. Shafiullah Parvej ${ }^{1}$, Marzia Rahman ${ }^{1 *}$, Md. Forhad Uddin ${ }^{2}$, KHM Nazmul Hussain Nazir ${ }^{1}$, \\ Md. Sayduzzaman Jowel ${ }^{1}$, Md. Ferdousur Rahman Khan ${ }^{1}$, Md. Bahanur Rahman ${ }^{1}$
}

${ }^{l}$ Department of Microbiology and Hygiene, Bangladesh Agricultural University, Mymensingh-2202, Bangladesh ${ }^{2}$ Department of Microbiology, University of Chiitagong, Chittagong, Bangladesh

\section{A R T I C L E I N F O}

Article history:

Received 29 February 2016

Accepted 17 May 2016

Available online, ISSN: 2148-127X

\section{Keywords:}

Layer chicken

Salmonella Typhimurium

PCR

Drug resistance

Antibiotic

${ }^{*}$ Corresponding Author:

E-mail: marzia_micro@yahoo.com \begin{abstract}
A B S T R A C T
Salmonella is considered as a global problem ranking first among food borne diseases. All motile Salmonella of poultry origin are zoonotic and readily transmit to human via meat and eggs but reports on non - typhoidal Salmonella serovars circulating in layer chickens is very limited in South-East Asian countries including Bangladesh. Salmonella serovars isolated from apparently healthy chickens were characterized in the present study. Of 170 samples (cloacal swab 150 and feed 20) collected from commercial layer farms, motile Salmonella was isolated $4 \%(6 / 150)$ and $50 \%(10 / 20)$ respectively by cultural, biochemical, motility test and by detection of hisJ gene. About 5\% (8/170) samples possessed serovar-specific gene fimA, suggesting that isolates were Salmonella enterica serovar Typhimurium. Antimicrobial susceptibility testing demonstrated that the isolated serovars were multidrug resistant. Therefore apparently healthy layer chickens harbour and transmit S. Typhimurium to the environment, although little is alarming since it has zoonotic significance and the isolates were resistant to commonly used first line of antibiotic in Salmonella infection.
\end{abstract}

\section{Introduction}

Food-borne bacterial pathogens are the important causes of human mortality worldwide especially in underdeveloped, least developed and developing countries. Salmonella is considered one of the most pathogenic and common zoonotic food borne bacteria (Baird-Parker, 1990). About 1.3 billion nontyphoideal salmonellosis have been reported annually in the world resulting 2 million deaths (Payment and Riley, 2002).

The major documented sources of Salmonella are the foods of animal origin. Salmonella infections might be occurring due to improper cooking methods and unhygienic handling of foods (Gorman et al, 2002). S. enterica serovar Typhimurium was the most commonly isolated Salmonella serotype from humans in the Republic of Ireland in 2001 (NDSC, 2001). As Salmonella is a pathogen resides in the gut of poultry, cross-contamination happens during processing of the Salmonella reservoir poultry for food preparation (Bryan and Doyle, 1995).

The drug resistant pathogens have been increased during recent years (Threlfall et al., 2000, Himi et al., 2015; Khatun et al., 2105, Tanzin et al., 2016). Presence of multidrug resistant bacteria in ready to eat foods is a global public health problem and sensitive bacteria readily converted to resistant one due to transfer of resistant gene.
Poultry and poultry products are the main source of human Salmonellosis since poultry are the most crucial reservoirs of Salmonella (Humphrey, 2000). In our previous report it was mentioned about $7 \%$ of healthy layer chicken in Bangladesh act as a source of multidrug resistant non motile Salmonella spp. during defecation (Parvej et al., 2016) but investigation on motile serovars of Salmonella in layer chickens is not reported yet. The multidrug resistant pathogenic Salmonella spp. circulating in some geographical areas is the great upcoming global problem because of their chances of transmission by travellers or trades of poultry and poultry products from infected countries.

Identification of the accurate source of Salmonella spp. at the geographical origin is only the way to control zoonotic Salmonella serovars globally for which knowledge on molecular epidemiology and local prevalence of the pathogen is very important (Collard et al., 2007). The study was conducted with a view to investigate the prevalence of $\mathrm{S}$. Typhimurium in apparently healthy layer chickens of Bangladesh and also to analyse the present status of antibiotic sensitivity pattern of the Salmonella serovars circulating in the country. 


\section{Materials and Methods}

\section{Sample Collection and Processing}

A total of 150 cloacal swab samples and 20 feed samples were collected from 4 commercial poultry farms located in Mymensingh, Bangladesh and inoculated into nutrient broth ( Himedia, India) followed by incubation at $37^{\circ} \mathrm{C}$ for 2 hours for enrichment. The samples were collected following a convenience method without repetition of any bird.

\section{Isolation and Identification of Salmonella Spp.}

Isolation of Salmonella was performed according to the method of Rybolt et al. (2005) with some modification. In short, the nutrient broth ( Himedia, India) containing cloacal samples were incubated for 2 hours at $37^{\circ} \mathrm{C}$ and then inoculated onto SS agar followed by overnight incubation at $37^{\circ} \mathrm{C}$. The feed samples were weighed about $25 \mathrm{gm}$ and $10 \%(\mathrm{w} / \mathrm{v})$ solution was prepared using phosphate buffer saline from which 0.1 $\mathrm{mL}$ of each sample was inoculated into SS agar (Himedia, India) and incubated at $37^{\circ} \mathrm{C}$ for overnight. The plates were examined for typical colony characteristics produced by Salmonella spp. Salmonella suspected colonies from SS agar were sub cultured into XLD agar (Himedia, India) to obtain pure culture of the isolates. The isolated organisms were identified by Gram's staining method to determine their staining characteristics, morphology, and arrangements. Five basic sugar fermentation (glucose, maltose, lactose, dulcitol and mannitol) tests were performed to identify the organism. The pure colony was identified by indole test, Methyl red and VP test. Then the motility test was performed by hanging drop slide method (Shanson, 1989) and by culturing onto Motility Indole Urea (MIU) media ( Himedia, India). Finally, the isolates were differentiated from group D Salmonella (non-motile Salmonella) by slide agglutination test using group $\mathrm{D}$ antigen ( $\mathrm{S}$ and $\mathrm{A}$ reagent lab, Bangkok, Thailand). The isolated Salmonella were further confirmed as $\mathrm{S}$. Typhimurium by PCR.

\section{Amplification of hisJ and fimA genes by PCR}

Genomic DNA of each bacterial isolate was prepared according to the method of Queipo-Ortun et al. (2008) with little modification. Briefly, $1 \mathrm{~mL}$ of overnight broth cultures of the isolate was centrifuged at $10000 \mathrm{rpm}$ for 5 minutes. Supernatant was discarded and pellet was mixed in $200 \mu \mathrm{l}$ of sterile distilled water by pipetting. The mixture was boiled for 10 minutes followed by cooling on ice and centrifugation at $10,000 \mathrm{rpm}$ for 5 minutes. The supernatants were collected to use as DNA template in PCR.

To detect and identify the isolates as Salmonella spp. performed PCR to amplify Salmonella specific gene hisJ using the oligunucleotides primers upper strand (5'ACTGGCGTTATCCCTTTCTCTGGTG-3'), and lower strand was (5'-ATGTTGTCCTGCCCCTGGTAAGAGA3') described by Noah et al., (1993) and the amplicon size was $496 \mathrm{bp}$. To make $25 \mu \mathrm{L}$ of reaction mixture, $1 \mu \mathrm{L}$ template DNA, $12.5 \mu \mathrm{L}$ of $2 \mathrm{X}$ Master Mix (Promega,
USA), $1 \mu \mathrm{L}$ of $10 \mathrm{pmol} / \mu \mathrm{L}$ of each primer and $9.5 \mu \mathrm{L}$ of sterile distilled water were taken and mixed well. Thermal cycler conditions were set as 30 cycles of $94^{\circ} \mathrm{C}$ for 30 seconds, $65^{\circ} \mathrm{C}$ for 30 seconds, $72^{\circ} \mathrm{C}$ for 45 seconds and an initial denaturation at $94^{\circ} \mathrm{C}$ for 5 minutes with final extension at $72^{\circ} \mathrm{C}$ for 7 minutes.

To confirm the isolates as Salmonella Typhimurium another PCR was performed using the primers set of FimA-F, 5'-CCT TTC TCC ATC GTC CTG AA-3' and FimA-R, 5'-TGG TGT TAT CTG CCT GAC CA3'(Angela et al., 2007). PCR mixture was prepared by previously describe method for hisJ gene detection. The fimA genes were amplified by 20 cycles of denaturation at $94^{\circ} \mathrm{C}$ for 1 minute, annealing at $58^{\circ} \mathrm{C}$ for 30 seconds. and elongation at $72^{\circ} \mathrm{C}$ for 1 minute with an initial denaturation at $94^{\circ} \mathrm{C}$ for 5 minutes and final elongation at $72^{\circ} \mathrm{C}$ for 5 minutes.

The PCR products were separated by gel electrophoresis using $1.0 \%$ agarose gel stained with ethidium bromide. The stained PCR products were visualized under UV-transillumninator (UVsolo TS, BioRad, Germany) and the results were recorded.

\section{Antibiotic Susceptibility Test}

Antibiotic Susceptibility of all isolated $\mathrm{S}$. Typhimurium was investigated by agar disc diffusion test on Muller Hinton agar (Himedia, India) according to CLSI (2007). The standardized commercial antibiotic discs used were : amoxycillin (10 mcg), ampicillin (10 $\mathrm{mcg}$ ), ciprofloxacin (5 mcg), doxycycline (30 $\mathrm{mcg})$, gentamycin $(10 \mathrm{mcg})$, kanamycin $(30 \mathrm{mcg})$, and tetracycline $(30 \mathrm{mcg})$ (Oxoid, UK).

\section{Results}

In the present study, S. enterica serovar Typhimurium was isolated and characterized from commercial poultry farms in Bangladesh. The study demonstrated that, out of 170 samples 4\% (6/150) apparently healthy layer chickens and $50 \%(10 / 20)$ feed samples were found positive for Salmonella serovars which was detected by both conventional and molecular method. The prevalence of $S$. enterica serovar Typhimurium was about $1.33 \%$ $(2 / 150)$ and $30 \%(6 / 20)$ in clocal swab and feed samples respectively. On SS agar the Salmonella spp. produced translucent, smooth, small round colonies with black centre (Hyeon et al., 2012). Gram's staining of the suspected colonies revealed Gram-negative, pink colored short rod shaped bacteria, arranged either single or paired. All of the tested isolates were indole and VP negative whereas Methyl red positive. All the isolates fermented glucose and maltose and produced both acid and gas. The isolates were confirmed as Salmonella spp. by amplification of hisJ gene (496 bp) (figure 1 and 2). A total of eight isolates were found to be motile characterized by forming the stab line without producing turbidity in MIU medium. The fimA gene (amplicon sizes $85 \mathrm{bp}$ ) (Figure 3 and 4) were successfully amplified in all eight isolates. Antibiotic sensitivity test using 7 drugs revealed $87.5 \% \quad(7 / 8)$ strains were sensitive to 
Ciprofloxacin, $87.5 \%(7 / 8)$ isolates were resistant to ampicillin, amoxicillin, doxycycline, kanamycin, and $62.5 \%(5 / 8)$ were resistant to gentamycin and tetracycline.

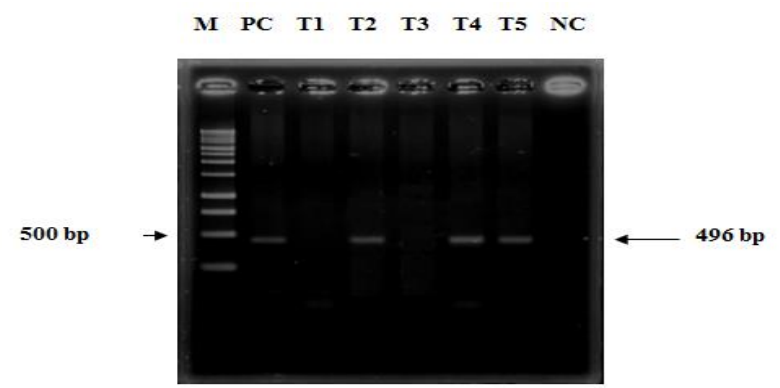

Figure 1 Electrophoretic analysis of PCR product to detect hisJ gene (Cloacal samples). Lane M: $1 \mathrm{~kb}$ DNA ladder ( Promega, USA), Lane PC: Positive control, Lane NC : Negative control, Lane T2,T4,T5: 3 positive Salmonella spp. of the study, Lane T1, T3 : Tested samples (Negative)

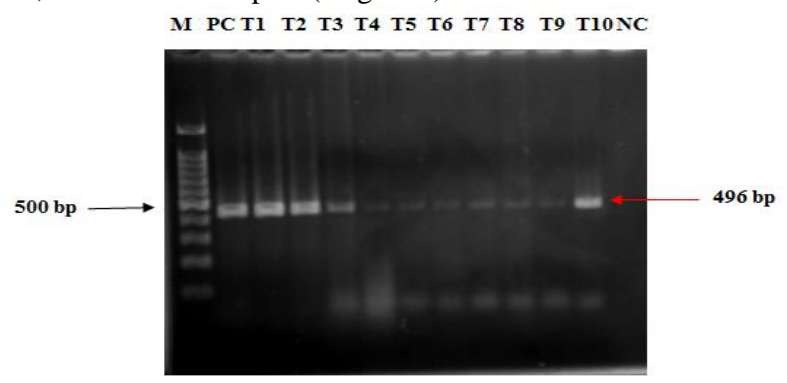

Figure 2 Electrophoresis analysis of PCR product to detect hisJ gene (Feed samples). Lane M: 100 bp DNA ladder (Promega, USA), Lane PC: Positive control, Lane NC: Negative control, Lane T1-T10: Ten Positive Salmonella spp.of the study.

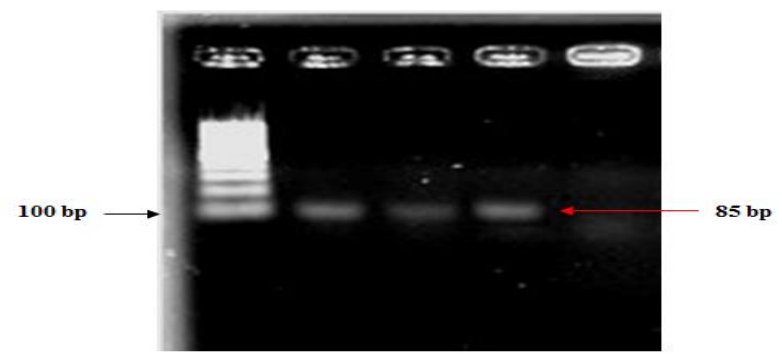

Figure 3 Electrophoresis analysis of PCR product to detect fimA gene (Cloacal samples). Lane M: 100 bp DNA ladder (Promega, USA), Lane PC: Positive control, Lane NC: Negative control, Lane T1, T2: 2 positive S. Typhimurium strain of the study

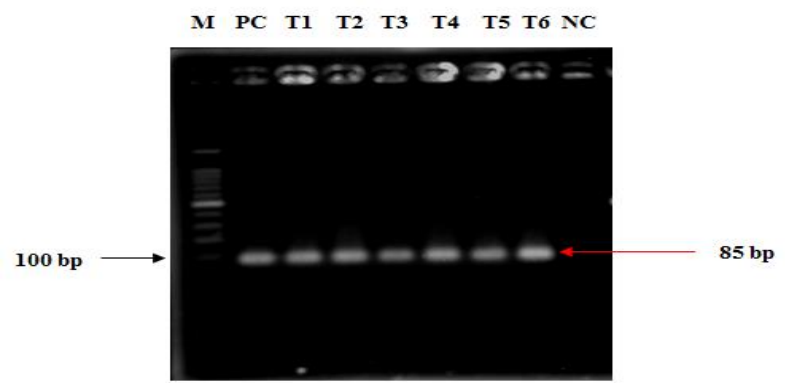

Figure 4 Electrophoresis analysis of PCR product to detect fimA gene (Feed samples). Lane M: 100 bp DNA ladder (Promega, USA), Lane PC: Positive control, Lane NC: Negative control, Lane T1 -T6: Six positive S. Typhimurium strain of the study.

\section{Discussion}

Salmonellosis is the most important food borne bacterial diseases in the world. Poultry and its products are considered as the major source for human Salmonellosis. Transmission of Salmonella spp. in poultry generation after generation is closely associated with infected eggs (Wigley et al., 2001). About 44.4\% of the chicken eggs are contaminated with Salmonella spp. in Bangladesh (Saha et al., 2012). Specific characterization of Salmonella isolates is therefore extremely important in order to control the Salmonella outbreak (Salehi et al., 2011; Gast, 1997). S. Typhimurium is the causal agent of typhoid fever, septicemia, and gastroenteritis in human (Tsen et al., 1994). The present study demonstrated that, about $4 \%$ of apparently healthy commercial poultry in Bangladesh carry Salmonella spp. which are readily spread into the environment through faeces and enter to human food chain by contaminated meats or eggs. Li et al., (2013) isolated 165 Salmonella isolates from 1382 samples (11.93\%) in China. Rahman et al. (2014) isolated salmonella specific bacteriophage from poultry farm of Bangladesh which also indicate the presence of Salmonella spp. in the surrounding environment of poultry farm because bacteriophages are present in that place where respective bacteria exist. In the present study it was found that, $50 \%$ of the feed samples which were supplied to the chicken contain salmonella. The contaminated poultry feeds might be the main source of infection in commercial poultry farms of Bangladesh. A total of $5 \% \mathrm{~S}$. Typhimurium were detected in both feed and cloacal samples by PCR. Separately about $1.33 \%$ layer chicken and $30 \%$ of poultry feed carry the same serovar. Angela et al. (2007) detected S. Typhimurium from raw chicken meat by amplification of fimA gene. Barua et al. (2012) isolated $18 \%$ motile Salmonella from layer farms in Chittagong region of Bangladesh and Salmonella Kentucky was isolated in that geographical location of the country. In our study we have isolated and identified S. Typhimurium in the layer farms of Mymensingh region. To the best of our Knowledge, only two serovars of motile Salmonella spp. have been identified in Bangladesh till date. In Bangladesh contaminated animal proteins are used as feed which may be main sources of Salmonella serovars in poultry (Papadopoulou et al., 2009). Farmers purchase the ingredient separately from local markets to produce poultry feed at low-cost. There are many poultry farmers use locally produced feeds from non-registered feed company; hygienic conditions of those feeds are questionable. The Salmonella spp. might be entered into poultry farm through vehicles because the same vehicles are used in Bangladesh for transportation of chicken, utensils, eggs and feeds from farms to market and vice versa. These vehicles become contaminated with faeces containing salmonella and transfer the pathogen from farm to market and farm to farm within country and between countries during import and export of poultry and poultry products. Ellerbroek et al., (2010) isolated 
$13 \%$ Salmonella from 400 imported chicken carcasses in Bhutan with $49.4 \%$ from swabs and $34.8 \%$ of the lymph nodes of pigs from Vietnam were Salmonella positive.

It is the matter of concern that, we observed high level of resistance (About 87\%) toward ampicillin, which is alarming for Bangladesh because of first choice of drug for treatment of systemic salmonellosis in humans until 1980s (Karki et al., 2013). Zou et al. (2012) reported that only $2.35 \%$ of the Salmonella isolated from North Carolina, USA were resistant to ampicillin and Fernandez et al. (2003) reported $13.6 \%$ isolates from Sao Paulo State of Brazil to be resistant to the same antibiotic. They did not observe Salmonella isolates resistant to ciprofloxacin but in our study about $13 \%$ isolates were resistant to this antibiotic. This situation in Bangladesh has been arises due to continuous use of antibiotics without proper guidance from registered veterinary practitioner. The farmers use antibiotics as growth promoter and for the treatment of different diseases without any proper guideline by the respective authorities, where they don't maintain proper dose and accurate antibiotics which leads to emergence of drug resistance pathogen in the environment. The accurate dose of antibiotic to poultry or any other animal should be carefully controlled otherwise it will become a great global problem because of wide host range of Salmonella spp. and its serious zoonotic significance.

\section{Conclusion}

The present study showed the presence of multidrug resistant S. Typhimurium in commercial poultry farms of Bangladesh which is the matter of concern for the authorities since food contamination and food borne pathogens are the global problem. To control multidrug resistant Salmonella spp. farmers should careful about the appropriate use of antimicrobials in poultry and need regular monitoring by the authorities

\section{Acknowledgements}

The authors are grateful to all researchers of the Department of Microbiology and Hygiene, Bangladesh Agricultural University, Mymensingh-2202, Bangladesh

\section{References}

Angela NM, Fabricio RC, Rita CSC, Roberta JR, Jose BC, Odir AD, Jose AGA. 2007. Detection of Salmonella Typhimurium in Raw Meats using In-House Prepared Monoclonal Antibody Coated Magnetic Beads and PCR Assay of the fimA Gene. J. Immuno. Immunochemis., 29:58-69

Baird-Parker AC. 1990. Foodborne Salmonellosis. Lancet, 336: 1231-1235.

Barua H, Biswas PK, Olsen KEP, Christensen JP. 2012. Prevalence and Characterization of Motile Salmonella in Commercial Layer Poultry Farms in Bangladesh. PLoS ONE, 7: e35914.

Bryan FL, Doyle MP.1995.Health risks and consequences of Salmonella and Campylobacter jejuni in raw poultry. J Food Prot., 58: 326-344.
CLSI. 2007. Enterobactericea. Performance standards for antimicrobial susceptibility testing; 17th informational supplement. CLSI document M100-S17, 27:32-35.

Collard JM, Place S, Denis O, Rodriguez-Villalobos H, Vrints M. 2007. Travel-acquired salmonellosis due to Salmonella Kentucky resistant to ciprofloxacin, ceftriaxone and cotrimoxazole and associated with treatment failure. J Antimicrob. Chemother., 60:190-192.

Ellerbroek L, Narapati D, Phu Tai N, Poosaran N, Pinthong R, Sirimalaisuwan A, Tshering P, Fries R, Zessin KH, Baumann M, Schroeter A. 2010. Antibiotic resistance in Salmonella isolates from imported chicken carcasses in Bhutan and from pig carcasses in Vietnam. J Food Protec., 73: 376-379.

Fernandes SA, Ghilardi ACR, Tavechio AT, Machado AMO, Pignatari ACC. 2003. Phenotypic and molecular characterization of Salmonella Enteritidis strains isolated in São Paulo, Brazil. Rev Inst Med Trop Sao Paulo, 45:59-63

Gast RK. Paratyphoid Infections. Diseases of Poultry. 10th ED. 1997. Iowa State University press. Ames, IA, 97-121.

Gorman R, Bloomfield S, Adley CC. 2002. A study of crosscontamination of food-borne pathogens in the domestic kitchen in the Republic of Ireland. Int J Food Microbiol., 76: 143-50.

Himi HA, Parvej MS, Rahman MB, Nasiruddin KM, Ansari WK, Ahamed MM. 2015. PCR Based Detection of Shiga Toxin Producing E. coli in Commercial Poultry and Related Environments. Turk. J. Agri. - Food Sci. Tech., 3: 361-364

Humphrey T. 2000. Public health aspects of Salmonella infection. In: Salmonella in Domestic Animals (C. Wray and A. Wray, eds.), CABI Publishing, 245-262.

Karki S, Shakya P, Cheng AC, Dumre SP, Leder K. 2013. Trends of etiology and drug resistance in enteric fever in the last two decades in Nepal: a systematic review and meta-analysis. Clin. Infect. Dis., 57: e167-76

Khatun MN, Mahbub-E-Elahi ATM, Ahmed S, Parvej MS, Akhter S, Ansari WK, Ali MS. 2015. Frequency of drug resistant Escherichia coli isolated from commercial broiler chicken in Bangladesh. Int. J. Nat. Soc. Sci., 2: 01-05.

Li R, Lai J, Wang Y, Liu S, Li Y, Liu K, Shen J, Wu C. 2013. Prevalence and characterization of Salmonella species isolated from pigs, ducks and chickens in Sichuan Province, China. Int J Food Microbiol., 15:14-18.

National Disease Surveillance Centre (NDSC). 2001. Annual report, 2001.

Noah DC, Holly LN, Edward DM, Howard WW, Robert WB, Pamela MR, Hargis BM. 1993. Genus-specific detection of Salmonellae using the polymerase chain reaction (PCR). J Vet Diagn Invest., 5: 368-371.

Papadopoulou C, Carrique-Mas JJ, Davies RH, Sayers AR. 2009. Retrospective analysis of Salmonella isolates recovered from animal feed in Great Britain. Vet Rec., 165: 681-688.

Parvej MS, Nazir KHMNH, Rahman MB, Jahan M, Khan MFR, Rahman M. 2016. Prevalence and characterization of multi-drug resistant Salmonella Enterica serovar Gallinarum biovar Pullorum and Gallinarum from chicken, Vet. World, 9: 65-70.

Payment P, Riley MS. 2002. Resolving the global burden of gastrointestinal illness: a call to action. A report from American Academy of Microbiology. Washington DC: American Academy of Microbiology: 26.

Queipo-Ortun M, De Dios Colmenero J, Macias M, Bravo MJ, Morata P. 2008. Preparation of Bacterial DNA Template by Boiling and Effect of Immunoglobulin $G$ as an Inhibitor in Real-Time PCR for Serum Samples from Patients with Brucellosis. Clin Vaccine Immunol., 15: 293-296.

Rahaman MT, Rahman M, Rahman MB, Khan MFR, Hossen ML, Parvej MS, Ahmed S. 2014. Poultry Salmonellaspecific bacteriophage isolation and characterization. Bangladesh J. Vet. Med., 12: 107-114

Rybolt ML, Wills RW, Bailey RH. 2005. Use of secondary enrichment for isolation of Salmonella from naturally contaminated environmental samples. Poultry Sci., 84: 992-997 
Saha AK, Sufian MA, Hossain MI, Hossain MM. 2012. Salmonellosis in layer chickens: pathological features and isolation of bacteria from ovaries and inner content of laid eggs. J Bangladesh Agri Univ., 10: 61-67.

Salehi TZ, Madadgar O, Tadjbakhsh H, Mahzounieh MR, Feizabadi MM. 2011. A molecular study of the Salmonella entericaserovars Abortusovis, Typhimurium, and Enteritidis. Turk. J. Vet. Anim. Sci., 35: 281-294

Shanson DC. 1989. Microbiology in Clinical Practice. Second edition. Butterworth and Co. Publishers limited, London. pp. 24.

Tanzin T, Nazir KHMNH, Zahan MN, Parvej MS, Zesmin K, Rahman MT. 2016. Antibiotic resistance profile of bacteria isolated from raw milk samples of cattle and buffaloes. J. Adv. Vet. Anim. Res., 3: 62-67.
Threlfall EJ, Ward LR, Frost JA, Willshaw GA. 2000. The emergence and spread of antibiotic resistance in food-borne bacteria. Int J Food Microbiol., 62: 1-5.

Tsen HY, Liou JW, Lin CK. 1994. Possible use of polymerase chain reaction method for specific detection of Salmonella in beef. $\mathrm{J}$ Ferment Bioeng., 77:137-143.

Wigley P, Berchieri AJ, Page KL, Smith AL, Barrow PA. 2001. Salmonella enterica serovar pullorum persists in splenic macrophages and in the reproductive tract during persistent, disease free carriage in chickens. Infect. Immun., 69: 7873- 787

Zou M, Keelara S, Thakur S. 2012. Molecular characterization of Salmonella entericaserotype Enteritidis isolates from humans by antimicrobial resistance, virulence genes, and pulsed-field gel electrophoresis. Foodborne Pathog Dis., 9:232-238 